\title{
Domestic smoke pollution and chronic bronchitis in a rural community of the Hill Region of Nepal
}

\author{
MRIGENDRA RAJ PANDEY \\ From the Department of Medicine, Bir Hospital, and the Institute of Medicine, Tribhuvan University, \\ Kathmandu, Nepal
}

ABSTRACT An earlier study of chronic bronchitis in a rural community of the Hill Region of Nepal using Medical Research Council criteria showed a high prevalence rate that was more or less equal in the two sexes. Most of the women in the study population are exposed to domestic smoke caused by wood and straw fires used for cooking and heating purposes in the ill ventilated houses without chimneys. Data from 1375 individuals were analysed to determine whether there was any relationship between domestic smoke pollution and chronic bronchitis. Exposure to domestic smoke was assessed according to the average time per day spent near the fireplace. The association between chronic bronchitis and cigarette smoking was confirmed. In female nonsmokers and smokers and past smokers of both sexes crude and age adjusted prevalence rates for chronic bronchitis were significantly associated with increasing exposure to domestic smoke. In the living conditions existing in the rural Hill Region of Nepal domestic smoke pollution is an important contributing factor in the development of chronic bronchitis.

A study of chronic bronchitis in a rural community of the Hill Region of Nepal (pp 331-6) using Medical Research Council criteria showed a very high prevalence of the disease, $17.6 \%$ among men and $18.9 \%$ among women. Whereas most other studies have shown a male preponderance, this study showed more or less equal prevalence rates in the two sexes. This high prevalence in women may be due to the exposure to domestic smoke caused by wood and straw fires used for cooking and heating in the ill ventilated houses without chimneys. Relative equality of prevalence rates in the two sexes was also found in studies carried out in Papua New Guinea among people with similar living conditions and similar exposure to domestic smoke pollution. This suggests that domestic smoke pollution may be an important contributing factor in chronic bronchitis. There has, however, been little direct support for this hypothesis. The data of the study conducted in the rural Hill Region of Nepal have been further analysed to find out if there is any association between domestic smoke pollution and chronic bronchitis.

\footnotetext{
Address for reprint requests: Dr MR Pandey, PO Box 2587, 1/257 Thapathali, Kathmandu, Nepal.
}

Accepted 27 January 1984

\section{Methods}

The methods used, the study population, data collection, and the definition of chronic bronchitis are the same as those described in the previous paper.

\section{SMOKING HABIT}

Smokers were defined as those who regularly smoke one or more cigarettes or equivalents a day.

Past smokers were defined as those who have ever smoked one or more cigarettes or equivalents a day for as long as one year but now smoke less than this. Non-smokers were defined as those who have never smoked or have smoked less than one cigarette or equivalent a day for as long as a year.

EXPOSURE TO DOMESTIC SMOKE POLLUTION Domestic smoke is produced by burning biomass fuel such as firewood and straw for cooking and heating. Houses are ill ventilated and have no chimneys. Most of the houses have only two or three rooms. The cooking is done on traditional stoves in a corner of one of the ground floor rooms and takes place in the morning and evening as villagers take only two main meals a day, at about 9 am and $7 \mathrm{pm}$. Most houses are heated by means of a fire in a fireplace known as an ageno dug on the floor of the ground floor room; this has a few bricks or stones 
surrounding it but no chimney. Members of the family sit round the ageno in the morning and evening to keep themselves warm. The fire is extinguished when the occupants of the house go to sleep so the sleeping quarters are not smoky during the night.

As most of the subjects in the study were found to be exposed to smoke for less than six hours a day we divided the exposure levels into four categories according to the average time, in hours, spent each day near the fireplace: (1) $0-0.9$ hours; (2) $1-1.9$ hours; (3) 2-3.9 hours; and (4) more than four hours. Ninety eight per cent of the last group were exposed to smoke for from four to six hours a day and none was exposed for more than eight hours.

All the statistical comparisons were made with a $\chi^{2}$ test. $\mathrm{P}$ values less than 0.05 were considered significant.

\section{Results}

We found a positive association between the smoking habit and the prevalence of chronic bronchitis in both men and women (men $\chi^{2}=35 \cdot 70, \mathrm{df}=1, \mathrm{p}<$ 0.01 ; women $\chi^{2}=17.36$, df $=1, p<0.01$ ). To study the effect of exposure to domestic smoke pollution as an independent variable, data on the average amount of time per day spent near the fireplace and the crude and age adjusted prevalence rates of chronic bronchitis were analysed in relation to smoking habit (table). The $\chi^{2}$ test for trend was used for statistical analysis. It can be seen from the table that among the smokers a significant increasing trend in the prevalence rate in the four exposed groups was found in both sexes $\left(\right.$ men $\chi^{2}=127 \cdot 70, d f$
$=3, \mathrm{p}<0.001 ;$ women $\chi^{2}=41.23$, df $=3, \mathrm{p}<$ $0 \cdot 001)$. The prevalence of chronic bronchitis among non-smoking women was also found to increase significantly with the duration of time per day spent near the fireplace $\left(\chi^{2}=19.96, \mathrm{df}=3, \mathrm{p}<0.001\right)$. Among the non-smoking men no cases of bronchitis were found for the last two exposure levels and only two cases each for the other two levels. The absence of cases associated with the two higher exposure levels is perhaps due to the fact that very few nonsmoking men were exposed to the fire for more than two hours a day. Among the past smokers there was a statistically significant increase in prevalence of chronic bronchitis with increasing time spent near the fireplace in both sexes $\left(\right.$ men $\chi^{2}=29 \cdot 85, \mathrm{df}=3$, $\mathrm{p}<0.001$; women $\chi^{2}=8.29$, df $\left.=3, \mathrm{p}<0.05\right)$. After age adjustment the rates were little different from the crude ones and the trend persisted in all three groups-smokers, non-smokers, and past smokers.

\section{Discussion}

Our demonstration of the association between smoking and prevalence of chronic bronchitis is in agreement with the findings of most of the published studies summarised by Fletcher,' although Anderson from Papua New Guinea ${ }^{2}$ and Cookson and Mataka from Rhodesia ${ }^{3}$ failed to demonstrate a relationship between smoking and chronic bronchitis.

The high prevalence rate in women found in the present study cannot be explained on the basis of smoking habit alone as most of the women were

Prevalence of chronic bronchitis according to time per day spent near the fireplace

\begin{tabular}{|c|c|c|c|c|c|c|c|c|}
\hline \multirow{3}{*}{$\begin{array}{l}\text { Average timelday } \\
\text { (h) }\end{array}$} & \multicolumn{4}{|l|}{ Men } & \multicolumn{4}{|c|}{ Women } \\
\hline & \multirow[t]{2}{*}{$n$} & \multirow[t]{2}{*}{ Cases } & \multicolumn{2}{|c|}{ Prevalence (\%) } & \multirow[t]{2}{*}{$n$} & \multirow[t]{2}{*}{ Cases } & \multicolumn{2}{|c|}{ Prevalence (\%) } \\
\hline & & & Crude & Age adjusted & & & Crude & Age adjusted \\
\hline $\begin{array}{l}\text { SMOKERS } \\
0-0.9 \\
1-1.9 \\
2-3.9 \\
4+ \\
\text { Total }\end{array}$ & $\begin{array}{r}616 \\
223 \\
166 \\
72 \\
1077\end{array}$ & $\begin{array}{r}52 \\
64 \\
60 \\
35 \\
211\end{array}$ & $\begin{array}{r}8 \cdot 44 \\
28 \cdot 76 \\
36 \cdot 14 \\
48 \cdot 61 \\
19 \cdot 59\end{array}$ & $\begin{array}{r}8 \cdot 36 \\
28.90 \\
31 \cdot 10 \\
34 \cdot 47 \\
18 \cdot 62\end{array}$ & $\begin{array}{l}117 \\
209 \\
335 \\
194 \\
855\end{array}$ & $\begin{array}{r}9 \\
27 \\
84 \\
65 \\
185\end{array}$ & $\begin{array}{r}7.69 \\
12.92 \\
25.07 \\
33 \cdot 51 \\
21 \cdot 64\end{array}$ & $\begin{array}{r}7 \cdot 81 \\
13 \cdot 35 \\
24 \cdot 34 \\
28 \cdot 63 \\
20 \cdot 80\end{array}$ \\
\hline $\begin{array}{l}\text { NON-SMOKERS } \\
0-0.9 \\
1-1.9 \\
2-3 \cdot 9 \\
4+ \\
\text { Total }\end{array}$ & $\begin{array}{r}156 \\
41 \\
12 \\
14 \\
223\end{array}$ & $\begin{array}{r}2 \\
-\quad \\
-\quad 4\end{array}$ & $\begin{array}{l}1.38 \\
4.88 \\
- \\
-1.79\end{array}$ & $\begin{array}{l}2.42 \\
8.67 \\
- \\
=3.00\end{array}$ & $\begin{array}{r}64 \\
142 \\
185 \\
134 \\
525\end{array}$ & $\begin{array}{r}4 \\
6 \\
29 \\
27 \\
66\end{array}$ & $\begin{array}{r}6 \cdot 25 \\
4.23 \\
15 \cdot 67 \\
20 \cdot 14 \\
12 \cdot 57\end{array}$ & $\begin{array}{r}6.99 \\
4.91 \\
17.68 \\
19.87 \\
13.76\end{array}$ \\
\hline $\begin{array}{l}\text { PAST SMOKERS } \\
0-0.9 \\
1-1.9 \\
2-3 \cdot 9 \\
4+ \\
\text { Total }\end{array}$ & $\begin{array}{l}34 \\
14 \\
17 \\
10 \\
75\end{array}$ & $\begin{array}{r}1 \\
9 \\
10 \\
7 \\
27\end{array}$ & $\begin{array}{r}2.94 \\
64 \cdot 29 \\
58 \cdot 82 \\
70 \cdot 00 \\
36 \cdot 00\end{array}$ & $\begin{array}{r}1 \cdot 90 \\
40 \cdot 18 \\
45 \cdot 36 \\
58 \cdot 83 \\
24 \cdot 80\end{array}$ & $\begin{array}{r}9 \\
16 \\
26 \\
20 \\
71\end{array}$ & $\begin{array}{r}0 \\
3 \\
11 \\
9 \\
23\end{array}$ & $\begin{array}{l}\overline{18} \cdot 75 \\
42 \cdot 30 \\
45 \cdot 00 \\
32 \cdot 39\end{array}$ & $\begin{array}{l}\overline{13} .86 \\
33.97 \\
62.91 \\
28.75\end{array}$ \\
\hline
\end{tabular}


found to be very light smokers. This suggests that the high prevalence in the women is primarily due to the fact that they are much more exposed to domestic smoke.

There have been many reports showing a positive association between urban atmospheric ${ }^{4-7}$ and industrial pollution ${ }^{8-10}$ and the prevalence of chronic bronchitis. Many rural populations in many developing countries are regularly exposed to biomass smoke inside their houses but there have been few studies of the effect of such exposure on health. Woolcock and Blackburn ${ }^{11}$ in their report on chronic lung disease in the Papua New Guinea Highlands suggested that the practice of crowding together around wood fires in unventilated thatched huts seemed likely to be responsible for the high prevalence of chronic bronchitis. In his study from Papua New Guinea Anderson concluded that "Although there is no direct evidence, the most likely possibilities [as causes of chronic lung diseases] are domestic wood smoke and acute chest infections." 2

The present study has shown a significant correlation between prevalence of chronic bronchitis and exposure to domestic smoke pollution. The increasing trend of the prevalence rates as the level of exposure is increased, even after elimination of the age effect (table), establishes the fact that domestic smoke pollution is an important contributing factor in chronic bronchitis.

The relatively high prevalence rate seen in the past smokers in this study is perhaps due to the fact that most of the past smokers have given up smoking after developing symptoms. A similar high prevalence rate in past smokers was reported by the College of General Practitioners in Britain. ${ }^{12}$

Chronic bronchitis causes much morbidity in Nepal and has important socioeconomic implications. The present study has identified smoking and domestic smoke pollution to be the two most important contributing factors. Recently there has been great interest in the increasing problem of smoking in the developing world. But unfortunately very little attention has been given to the problem of pollution caused by domestic smoke produced by burning biomass fuels. To tackle this problem it will be necessary to develop appropriate technology to provide effective smokeless stoves with low fuel consumption. The stoves should be cheap, effective, acceptable, and really appropriate to the villagers' needs, allowing for their attitudes and traditions. The people have been accustomed to living in smoky houses for generations and the smoke has some positive effects, such as protecting wood and driving out mosquitoes. Alternative methods of wood preservation using cheap paints should be adopted. Efforts should be made to motivate the villagers to adopt the necessary changes in attitudes and behaviour. To make all this possible effective community participation, health education, and a general raising of the educational and socioeconomic stardards of the people are essential.

I with to express my most grateful thanks to all the hard working members of the team and also to the superintendent of Bir Hospital for providing facilities for investigation. The work was supported by grants from the National Council for Science and Technology and the Mrigendra Medical Trust.

\section{References}

' Fletcher CM. Cigarettes and respiratory disease. In: Goodman HA, ed. World conference on smoking and health: a summary of the proceedings. New York: American Cancer Society, 1968:78.

${ }^{2}$ Anderson HR. Chronic lung disease in the Papua New Guinea Highlands. Thorax 1979;34:647-53.

${ }^{3}$ Cookson JB, Mataka G. Prevalence of chronic bronchitis in Rhodesian Africans. Thorax 1978;33:328-34.

${ }^{4}$ Fairbairn AS, Reid DD. Air pollution and other local factors in respiratory disease. Br J Prev Soc Med 1958; 12:94-103.

${ }^{5}$ Holland WW, Reid DD. The urban factor in chronic bronchitis. Lancet $1965 ;$;:444-8.

- Lambert DM, Reid DD. Smoking, air pollution, and bronchitis in Britain. Lancet 1970; i:853-7.

${ }^{7}$ Waller RE. Control of air pollution: present success and future prospect. In: Bennett AI, ed. Recent advances in community medicine. Edinburgh: Churchill Livingstone, 1978.

${ }^{8}$ Lower CR. Chronic bronchitis and occupation. Proc $\boldsymbol{R}$ Soc Med 1968;61:98-102.

${ }^{9}$ Pemberton J. Occupational factors in chronic bronchitis. Proc R Soc Med 1968;61:95-8.

${ }^{10}$ Lebowitz MD. Occupational exposures in relation to symptomatology and lung function in a community population. Environ Res 1977;14:59-67.

"Woolcock AJ, Blackburn CRB, Freeman MH, Zystra W, Spring SR. Studies of chronic (nontuberculous) lung disease in New Guinea populations. Am Rev Respir Dis 1970;102:575-90.

12 College of General Practitioners. Chronic bronchitis in Great Britain: a national survey carried out by the respiratory diseases group of the College of General Practitioners. Br Med J 1961;ii:973-9. 